\title{
SPECIAL COMMUNICATION \\ DESIGN AND DEVELOPMENT OF IMPURITIES FREE PYROLYTIC COATED MECHANICAL BI-LEAFLET HEART VALVE PROTOTYPE
}

\author{
Natasha Mukhtiar ${ }^{1}$, Murtaza Najabat Ali ${ }^{1}$, Hafsa Inam ${ }^{1}$ \\ ${ }^{1}$ Biomedical Engineering and Sciences Department (BMES), School of Mechanical and Manufacturing Engineering (SMME), National \\ University of Sciences \& Technology (NUST), Islamabad, Pakistan
}

\begin{abstract}
Heart valve problems affect more than 100 million people worldwide. According to statistics, around $55 \%$ of valvular diseases are treated by a mechanical prosthesis. The first heart valve replaced model was the caged-ball valve, more than 50 models of heart valves designed by different companies. Each design has different aspects such as valve geometry, leaflets design, materials used for model manufacturing, coating techniques, and coating materials. Depending on the patient's need and condition, the native heart valve either replaced by a biological or mechanical heart valve. Biological valves are made of living tissues whereas mechanical valves manufactured by the biomaterials, which are biocompatible and do not causes any reaction inside the body. The prototype discussed in this paper provides good hemocompatibility, because of the biomaterial used in this prototype manufacturing. It will reduce tissue ingrowth, due to the enhanced leaflet ear of the orifice ring. Moreover, it will cause less thrombotic effects into the host due to greater contact angel of graphite and smooth surface of graphite after pyrolytic coating. The significant evolution of mechanical valve designs consists of valve geometry, coating technique, and materials. In this research, the 3D-CAD model of Bileaflet Mechanical Mitral Heart Valve was designed using SOLID WORKS 2016 and fabricated by 5 axis Computer Numeric Control (CNC) machine. Graphite was used for the fabrication of prototype and Pyrolytic Carbon (PyC) coating was performed with Chemical Vapor deposition (CVD) technique. Scanning electron microscopy (SEM), Fourier Transform Infrared Spectroscopy (FTIR), and X-ray Diffraction (XRD) were used to determine the effects of CVD on surface topography and chemical structure of graphite model before and after coating. Furthermore, hemocompatibility of graphite and $\mathrm{PyC}$ analyzed through in-vitro hemolytic activity. The Characterization results showed that the Bileaflet Mechanical Mitral Heart valve prototype after $\mathrm{PyC}$ coating provides a smooth surface with improved hemocompatibility and less adhesion. Besides, the Mechanical Heart valves showed no hemolysis during the hemolytic activity. By virtue of its smooth and nonporous surface, it is antithrombotic and provides good hemodynamics. The advance long leaflet ear design reduces the tissue ingrowth around the orifice which will further limit the leaflets movement.
\end{abstract}

Keywords: Mechanical Heart valve, Biocompatibility, Biomaterials, Hemodynamics, Pyrolytic carbon Coating

Citation: Mukhtiar N, Ali MN, Inam H. Design and Development of Impurities Free Pyrolytic Coated Mechanical Bi-Leaflet Heart Valve Prototype. Pak Heart J. 2021;54(03):277-284. DOI: https://doi.org/10.47144/phj.v54i3.2114

\section{INTRODUCTION}

Heart valve diseases are the one of most leading cause of death all over the world. Most of the population affected by degenerative valve diseases, (like regurgitation, stenosis) stiffness of leaflets due to the high prevalence of rheumatic heart disorders especially in emerging countries. ${ }^{1}$ The most common problems in heart valves are regurgitation, stenosis, and atresia in these conditions blood continuously leak through the valves. ${ }^{2}$ The clot formation at the site of leakage leads to stroke, heart failure, and death. The abnormalities may occur in any valve but the most commonly replaced valve is mitral valve each year 40,000 mitral valves replaced. ${ }^{3}$ Heart valve prosthesis improves the quality of life when a person is suffering from any valvular disorder. These valves open and close naturally due to the gradient pressure of blood they have only one-way flow. ${ }^{4}$

The mitral valve present on the left side of the heart and it is consisting of two cusps it will open when atrial pressure becomes greater than ventricular pressure and whole blood is flushed out from one chamber to another during each cardiac cycle. Mitral valve defects comprise 2 million disorders caused by mitral regurgitation and 3 million by stenosis of the mitral valve. ${ }^{5}$ A diseased valve repaired or replaced by the surgeon depending on the condition of the patient. Although the total replacement of the valve takes time, because of the different choices available in the market and which one is perfect and compatible with the body. 
The prosthetic valve shows a tremendous role in saving the life of patient who is suffering from malfunctioning of the heart valve. ${ }^{6}$

There are two types of prostheses currently present in the market. Mechanical and Biological heart valves. Mechanical Heart valves completely made from biomaterials they have a long life span as compared to biological valves but they require anticoagulation therapy to prevent abnormalities in blood rheology. ${ }^{2}$ Whereas biological valves manufactured by the living tissues, they exhibit good biocompatibility and no need for anticoagulant but they have a short life span. In early ninety's caged ball valves were used as mechanical valves after these design scientists develop single leaflet mechanical heart valves and now they are using bileaflet mechanical valves. ${ }^{7}$ The bileaflet mechanical heart valves show improved hemodynamics as compare to caged ball valves and single leaflet mechanical valves. Multiple designs of Bileaflet Mechanical Mitral Heart Valves fabricated from different biomaterials with a variety of characteristics worldwide. Each model shows its unique characteristics because of biocompatibility and their life span in the host body. The efficiency of the heart valve depends on its model design and biocompatibility of selected biomaterials. ${ }^{5}$

Chemical Vapor Deposition (CVD): Chemical Vapor Deposition (CVD) is the most commonly used technique in materials sciences. It plays a vital role in surface modification and coating of different materials onto the substrate (base material). ${ }^{8}$ In CVD one or more layers of materials coated on the substrate using temperature, specific range of pressure and gaseous mixture as a precursor. In the simplest materialization, CVD includes flowing of gases into the vacuum chamber consist of one or multiple preheated substrates, and as a result of chemical reaction thin film deposition on the surface of the substrate. ${ }^{9}$ The excessive heat and byproducts eliminated from the chamber along with the non-reactant gases by a proper exhaust system to prevent the contamination into the reaction chamber. ${ }^{10}$

CVD provides thin uniform layers of coating, and through this technique, each side of the substrate coated with the same thickness. Another important factor of this technique is, due to the large variety of materials deposition, it provides a high rate of purity in the deposited material because during this process impurities removed from the substrates. The deposition rate of the CVD method is high as compare to other methods like Physical Vapor Deposition (PVD) or magnetron sputtering. ${ }^{11}$
Types of Mechanical Heart Valves: There are multiple types of bileaflet mechanical mitral heart valves manufactured by different companies. There are four different heart valves manufacturing companies discussed in this research. These heart valves differentiated according to their design, base material, coating techniques, hemocompatibility and hemodynamics, and their life span into the body as shown in Table 1.

Table 1: Types of Mechanical Heart Valves

\begin{tabular}{|c|c|c|c|c|}
\hline $\begin{array}{l}\text { Company } \\
\text { Name }\end{array}$ & $\begin{array}{l}\text { Valve } \\
\text { type }\end{array}$ & $\begin{array}{l}\text { Orifice } \\
\text { ring }\end{array}$ & Leaflet & Coating \\
\hline $\begin{array}{l}\text { St. Jude } \\
\text { Medical } \\
\text { (SJM) }^{12,13} \\
\text { Figure } 1\end{array}$ & Bileaflet & Graphite & $\begin{array}{c}\text { Graphite } \\
\text { with } \\
\text { PyC } \\
\text { Coatings }\end{array}$ & $\begin{array}{c}\text { PyC } \\
10 \% \\
\text { tungsten }\end{array}$ \\
\hline $\begin{array}{l}\text { Advancing } \\
\text { the Standard } \\
\text { (ATS) }^{14,15} \\
\text { Figure } 1 \\
\end{array}$ & Bileaflet & Graphite & $\begin{array}{c}\text { Graphite } \\
\text { with } \\
\text { PyC } \\
\text { Coatings }\end{array}$ & $\begin{array}{c}\text { PyC } \\
20 \% \\
\text { tungsten }\end{array}$ \\
\hline $\begin{array}{l}\text { Medtronic }{ }^{16,17} \\
\text { Figure } 5\end{array}$ & $\begin{array}{c}\text { Single } \\
\text { leaflet } \\
\text { and } \\
\text { Bileaflet }\end{array}$ & Titanium & $\begin{array}{c}\text { Graphite } \\
\text { with } \\
\text { PyC } \\
\text { Coatings }\end{array}$ & $\begin{array}{c}\text { PyC } \\
20 \% \\
\text { tungsten }\end{array}$ \\
\hline $\begin{array}{l}\text { On- } X^{8,18} \\
\text { Figure 1 }\end{array}$ & Bileaflet & $\mathrm{PyC}$ & $\mathrm{PyC}$ & $\begin{array}{c}\text { PyC } \\
\text { coating }\end{array}$ \\
\hline
\end{tabular}

Design inspiration for this research taken from the On-X mitral valve, because the On-X mechanical heart valves provide good hemodynamics and made of pure Pyrolytic Carbon. ${ }^{19}$ Its innovative design and progressive material increase the life span of prosthesis in human body without harming the surrounding tissue and blood cells. Surgeons prefer On-X heart valves because of its long life span with good hemocompatibility and patients with On-X heart valve require less warfarin and short-term anticoagulation therapy after implantation..$^{20,21} \mathrm{On}$ $\mathrm{X}$ heart valves by Cryolife USA are on top priority valve due to its unique design characteristics and density of PyC they using for the fabrication of heart valve models. The On-X heart valve is the clinically proven mechanical valve model, with a low dosage of anticoagulation as compared to other available models. During prospective clinical trials, On-X heart valves patients with reduce the dose of warfarin (anticoagulant) and causes less harmful effects when coming in contact with blood..$^{22,23}$

This research focuses on the three aspects, i) materials used for the fabrication of mechanical heart valve ii) coating techniques along with the coating material iii) hemocompatibility and surface morphology of biomaterials.

Therefore, the purpose of this research is to fabricate the leaflet mechanical mitral heart valve 
from graphite, further coated with $\mathrm{PyC}$ to improve the surface smoothness and hemocompatibility. The validation of $\mathrm{PyC}$ coatings carried out by the characterization techniques, and hemocompatibility

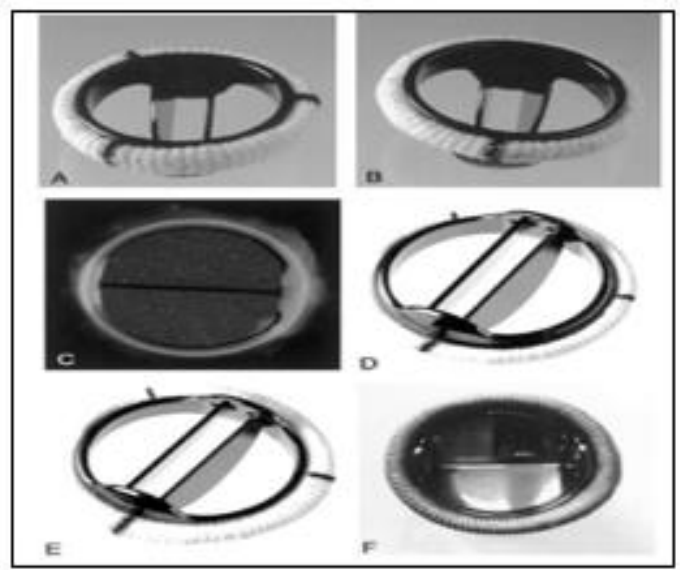

SJM Mechanical Heart Valve Models

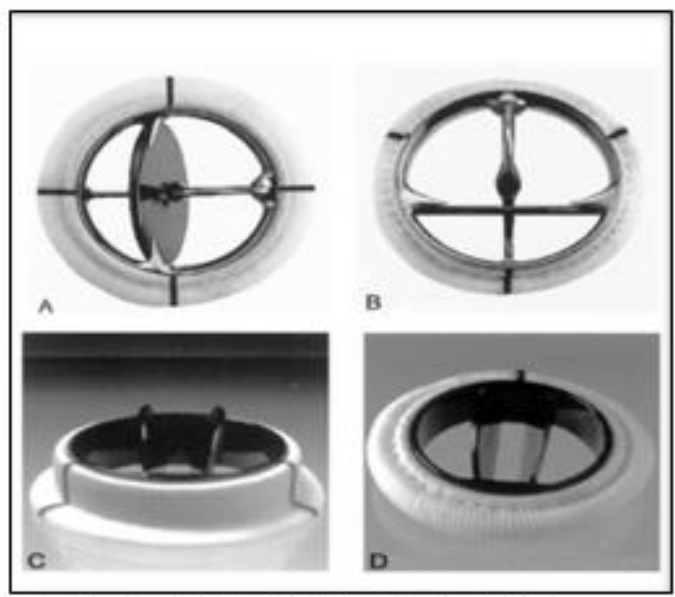

Medtronic Mechanical Heart Valve Models of material analyzed by the hemolytic activity according to ASTM Standard F756. ${ }^{24}$

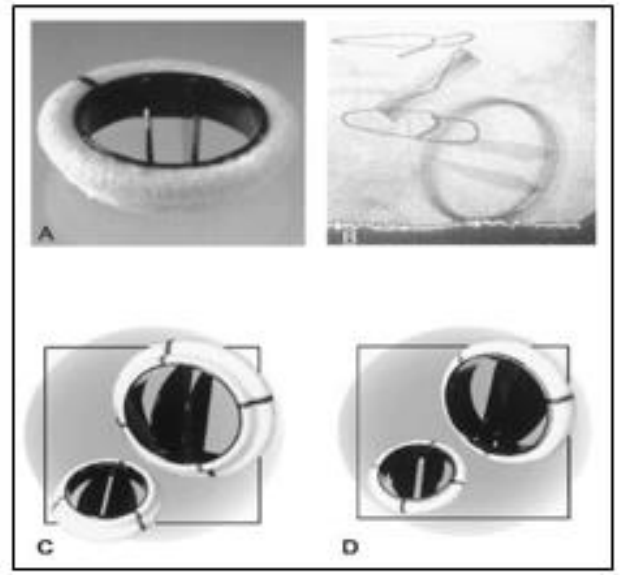

ATS Mechanical Heart Valve Models

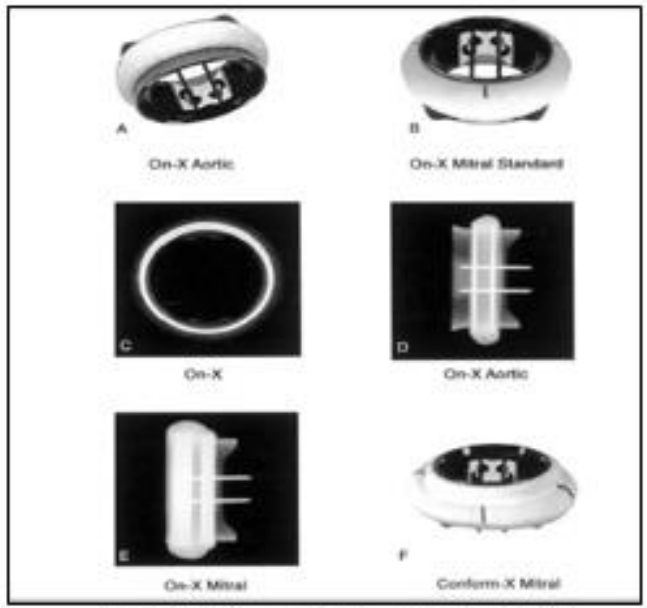

On-X Mechanical Heart Valve Models

Figure 1: Commercially available heart valve models

\section{MATERIAL AND METHODS}

The fabrication of Bileaflet Mechanical Mitral Heart Valve was carried out using graphite with $1.95 \mathrm{~g} / \mathrm{cm}^{3}$ density because of its reported hemocompatibility and antithrombotic behavior in biomedical applications. ${ }^{18}$ the 5-axis CNC machine was used for the fabrication of bileaflet mechanical heart valve whereas the PyC coating was done by the CVD technique.

\section{Fabrication of Mitral Heart Valve}

3D CAD Model designing: The 3D CAD model of Bileaflet Mechanical Mitral Heart Valve designed by the SOLIDWORKS 2016, as shown in Figure 2.

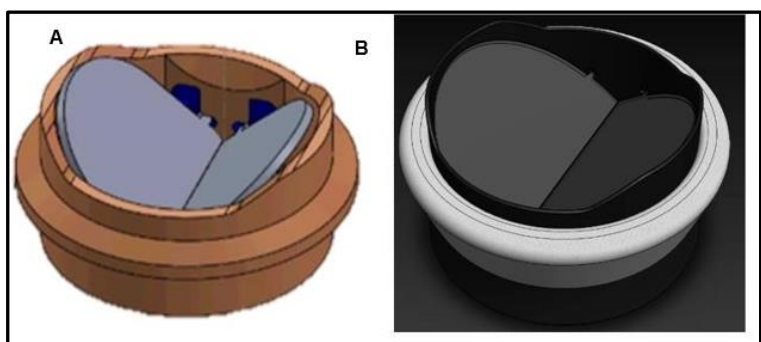

Figure 2: 3D CAD Model designed by Solid Works

CNC Machining: Graphite was selected as a base material for the fabrication. The graphite is brittle materials so the most challenging phase of this research was the fabrication of prototypes through 5-axis $\mathrm{CNC}$ to achieve complex geometry. The 5-axis CNC machine (YCM) at Power Wheels Industrial Estate Kot Lakhpat, 
Lahore Pakistan was used for the fabrication of a bileaflet mechanical mitral heart valve using graphite rod, as shown in Figure 3. CAD file introduced to the CNC machine by DELCAM software and further multiple cutting and grinding tools utilized for the fabrication of the final prototype.
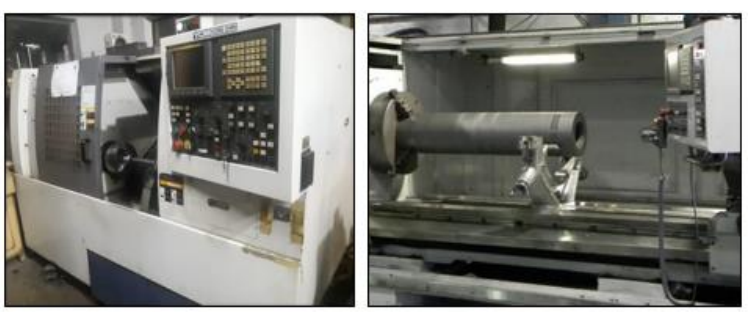

Figure 3: CNC Machine A. YCM B. Machining tool

The main parts of the prototype were two leaflets and external orifice after machining and finishing of final parts leaflets were assembled into the butterfly, shaped hinges engraved in orifice. Leaflets open and close to allow one-way blood flow and maximum degree of movement during each cardiac cycle. These leaflets prevent the mixing of blood between two chambers. As leaflet open maximum angle of $90^{\circ}$ was achieved, it allows the blood flow from one chamber to another chamber whereas at $0^{\circ}$ leaflet closes which preventing blood flow across the mechanical heart valve.

Coating of Mitral Heart Valve: The PyC carbon coating on the graphite models was carried out by the Chemical Vapor Deposition (CVD) method. CVD is a type of chemical reaction in which substrates were placed in a closed vacuum chamber and by the introduction of two or more gaseous mixtures, chemical reaction takes place between the substrate and gases in the presence of heat, resulting thin layer of PyC deposited onto the substrate. It was an extensive and hazardous method because of the high temperature in the reaction chamber and the pressure of gases. The gaseous pressure also maintained throughout the reaction, any mishandling may cause blast into the chamber.

Coating Parameters: The important parameters used during the CVD process along with their values are listed in Table 2.

Table 2: CVD coating parameters

\begin{tabular}{|l|c|}
\hline Parameters & Values \\
\hline Coating thickness & up to $0.5 \mu \mathrm{m}$ \\
\hline Deposition rate & $0.01 \mu / \mathrm{min}$ \\
\hline Temperature & $1000^{\circ} \mathrm{C}$ \\
\hline Pressure must be between & $1-5 \mathrm{Torr}$ \\
\hline Flow rate of Argon $999-1000$ & $50 \mathrm{sccm}^{*}$ \\
\hline Flow rate of $\mathrm{CH} 4 \& \mathrm{H} 1000$ & $20 \mathrm{sccm}^{*}$ \\
\hline
\end{tabular}

*sccm "standard cubic centimeters per minute"

Coating Process: The PyC coating was carried out by the CVD method using "Protherm by NanoVak" in the Energy System lab of USP-CASEN at National
University of Sciences and Technology Islamabad as shown in Figure 4.
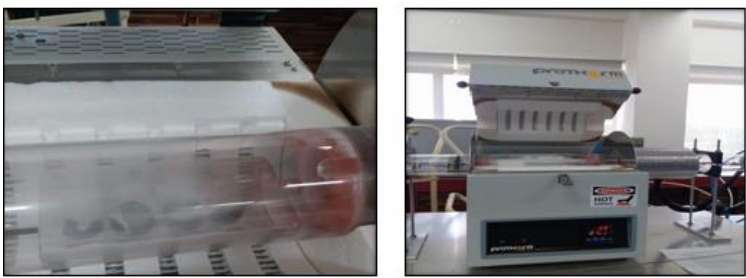

Figure 4: CVD Equipment A. Vacuum tube with coated samples B. CVD Unit

CVD apparatus used in this research was controlled by temperature and pressure. The temperature ranges for the chemical reaction set between $800-1000^{\circ} \mathrm{C}$. While three gases were used in the reaction, hydrogen $(\mathrm{H}), \operatorname{argon}(\mathrm{Ar})$ and methane (CH4). Ar was used as a carrier gas during the chemical reaction. In the graphical representation of the CVD method as shown in Figure 5 the first phase of the reaction, called the ramping temperature phase, during this phase, the surface of the substrate (graphite) was prepared for coating in which oxygen or any kind of impurity if present was removed. Subsequently, the temperature was incrementally increased from room temperature by the rate of $8^{\circ} \mathrm{C} / \mathrm{min}$, and simultaneously Ar flowed into the reaction chamber and this phase was completed in approx. 120-140min. After the ramping phase when the temperature reached up to $1000^{\circ} \mathrm{C} \mathrm{Ar}$ flow was stopped, during this phase pressure maintained between 1-5 Torr by adjusting the throttle valve. Throttle valve in CVD equipment considered as a safety valve by opening and closing of this valve the pressure of the reaction chamber maintained.

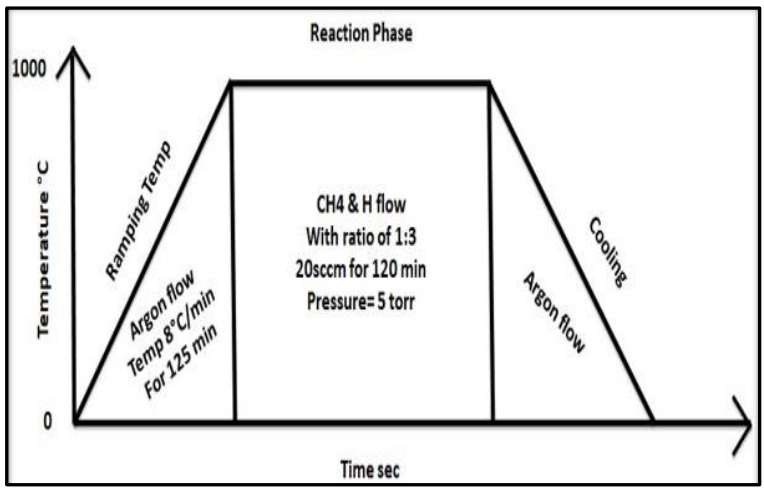

Figure 5: Graphical representation of CVD reaction

When the temperature reached up to $1000^{\circ} \mathrm{C}$ ramping phase terminated and the reaction phase started. In the reaction phase, $\mathrm{CH} 4$, and $\mathrm{H}$ gas flowed into the chamber in a ratio of $1: 3$ at $20 \mathrm{sccm}$ and pressure maintained between 1-5torr. The reaction phase completed in approx. 60-80min. During this phase, the substrate reacts with the gaseous mixture in presence of high temperature and pressure, the covalent bonds in the graphite structure 
squeezed later producing a thin layer on the graphite substrate, which is commonly called PyC. After completion of the second phase, the temperature of the substrate was brought back to room temperature in the third phase, called the cooling phase as shown in Figure 5. In the third phase of the CVD reaction, Ar was continuously flowing into the reaction chamber with a flow rate of $10-20 \mathrm{sccm}$ to avoid contamination and to remove remaining unwanted particles. Because of the squeezing of covalent bonds, the pore size of the graphite substrate reduced forming a shiny grey layer called PyC as shown in Figure 6.

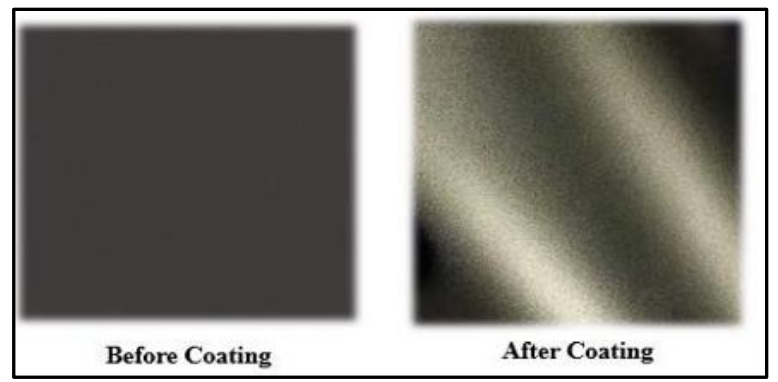

Figure 6: Samples before and after coating

Characterization Techniques: The morphology, chemical structure changes, and crystalline domains in graphite and $\mathrm{PyC}$ verified by the Scanning Electron Microscopy (SEM), Fourier Transform Infrared Spectroscopy (FTIR), and X-ray Diffraction (XRD). In this paper, changes occur in the material before and after coatings such as surface smoothness, bonding structure, and crystallinity of material analyzed by the characterization techniques.

Scanning Electron Microscopy (SEM) Analysis: SEM is the type of electron microscopy in which the surface of the materials was analyzed by using a high electron beam. These electrons interact with the material and produce information regarding surface topography and materials composition. SEM images give details about the surface topography and surface area of the sample. The assessment of surface morphology of graphite and PyC was done by the VEGA3 TESCAN Analytical scanning electron microscope (JEOL, Tokyo, Japan). The activation voltage for SEM analysis during this testing was $20 \mathrm{kV}$.

Fourier Transform Infrared Spectroscopy (FTIR) Analysis: FTIR is a characterization technique in which the infrared spectrum of absorption or transmission was obtained. It is an analytical technique used to find out the chemical bonding of the substrate. FTI spectroscopy was conducted using a Perkin Elmer spectrophotometer of spectrum 100 FTIR for the investigation of the chemical and physical interaction between the carbon atoms present in the graphite and pyrolytic carbon and how they are different from each other. FTIR analysis was carried out at 256 scans with a resolution of $8 \mathrm{~cm}-1$.

X-ray Diffraction (XRD) Analysis: For the investigation of the degree of crystallinity in the graphite and pyrolytic carbon, x-ray diffraction was performed. $\mathrm{XRD}$ is the analytical method for the investigation of crystalline domains in the chemical compound. By using an X-ray beam and detector sample can be analyzed and identify chemical compounds by using the peaks obtained at the output graph. X-ray diffraction patterns for this testing were obtained over the $2 \theta$ range of $10-40^{\circ}$.

Hemolytic Activity: In this paper, the hemotoxicity of graphite and $\mathrm{PyC}$ was carried out through invitro hemolytic activity using fresh human blood as shown in Figure 7. The $4 \mathrm{ml}$ of phosphate-buffered saline (PBS) was added in $2 \mathrm{ml}$ of the whole blood sample, subsequently, blood samples were centrifuged at 5,000 rpm for 5 min to isolate the RBCs. Furthermore, RBCs were washed with PBS thrice finally $2 \% \mathrm{RBCs}$ suspension was prepared in PBS for conducting the hemolytic activity. The suspension of RBCs (2\% v/v) was exposed to graphite and PyC. The $0.5 \%$ of Triton (X100) was used as positive control and PBS as a negative control for the hemolytic testing. After 4 hours of incubation at $37^{\circ} \mathrm{C}$, samples were centrifuged at $550 \mathrm{rpm}$ for $5 \mathrm{~min}$, the supernatant was collected and the absorbance was measured using UV spectrophotometry at $550 \mathrm{~nm}$. The hemolysis percentage for each sample was calculated by the following formula. ${ }^{25}$

\section{Hemolysis $=$ Absorbance of samples $/$ Absorbance of} positive control $\times 100$

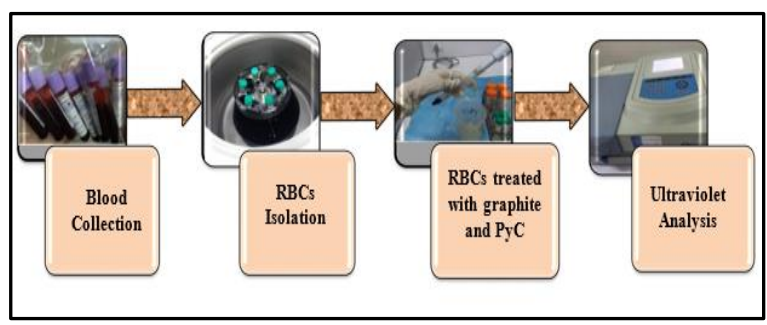

Figure 7: Steps of Hemolytic activity

\section{RESULTS AND DISCUSSIONS}

Scanning Electron Microscopy (SEM): The surface morphology of graphite and $\mathrm{PyC}$ was assessed by the SEM technique. It was estimated that changes occur in the surface of graphite after coating as shown in Figure 8. According to these SEM images, the surface area reduced due to the stretching of bonds after coating. The contact angle increased as surface area reduced and as a result, less adhesion occurs when material encountered to the blood or body fluid. ${ }^{26}$ The SEM images in Figure 8 was taken at $20 \mathrm{KV}$ voltage and 10-micron meter with X1500. 


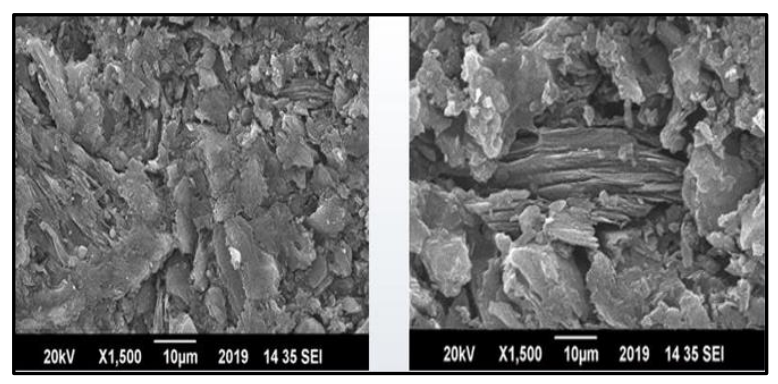

Figure 8: SEM Images A. Graphite B. PyC

The water droplet on the graphite surface produces a smaller contact angle producing wettability due to a slightly porous surface, which causes surface adhesion as shown in Figure 9 (A). Whereas the water droplet on the PyC surface shows greater contact angle as shown in Figure 9 (B), due to the non-porous surface, which shows decreasing in surface adhesion and the surface is said to be hydrophobic. This analysis validated the coating and the changes that occur in the chemical structure of graphite after coating. ${ }^{27}$

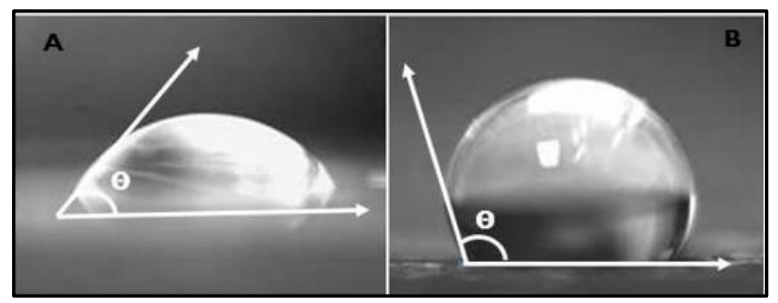

Figure 9: Contact angle A. Graphite B. PyC

Fourier Transform Infrared Spectroscopy (FTIR): The FTIR Spectrum of graphite and $\mathrm{PyC}$ is shown in Figure 10. The graph pattern for both compounds was the same due to their same chemical formula, while the only difference in $\%$ transmittance of radiations. The change in \% Transmittance material before and after coating was due to stretching of the chemical bond. The main constituent of both compounds was Carbon, Hydrogen, and the peaks at different values in the graph represent the bond between C-C at $3418 \mathrm{~cm}-3$ and $1632 \mathrm{~cm}-3$. The rest of the peaks at $11.19 \mathrm{~cm}-3$ and $372 \mathrm{~cm}-3$ are due to the realignment of $\mathrm{C}-\mathrm{H}$ bonds. The $\%$ transmittance of $\mathrm{PyC}$ starts from $72 \%$ and which decreases to $54 \%$ due to stretching of bond in $\mathrm{PyC}$ after CVD reaction. ${ }^{28}$

X-ray Diffraction (XRD): XRD patterns for graphite and PyC were obtained over the range of 0-1200 X-ray beam intensity at the angle of $2 \theta$. A broad characteristic peak of graphite was observed between $20^{\circ}-30^{\circ}$ due to its crystalline nature. The diffraction pattern exhibited a single sharp peak, which showed the presence of crystalline domains in graphite as shown in Figure 11(A). Graphite Peak intensity was 1400 because the intensity of the $\mathrm{X}$-ray beam in graphite was high.

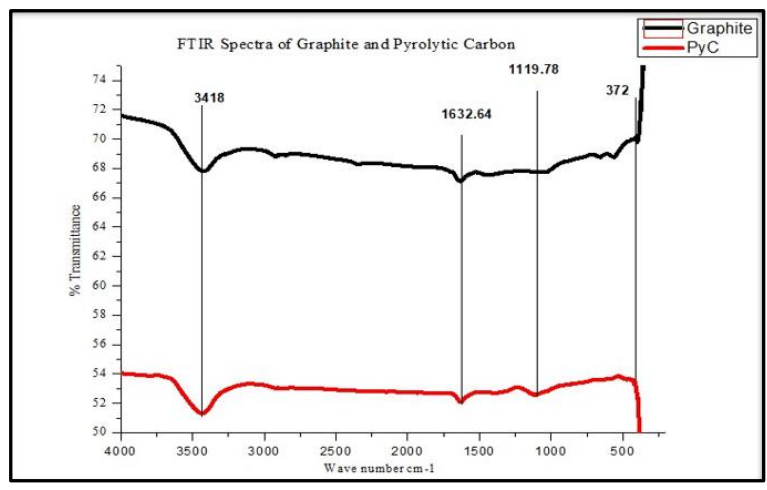

Figure 10: FTIR Analysis of Graphite and PyC

Whereas in the case of pyrolytic carbon XRD graphs as shown in Figure 11(B) represent the peak absolute intensity at 450 because of low X-ray beam intensity in PyC due to change in the crystalline structure of PyC. The bonds were squeezed in PyC as a result of CVD process and $\mathrm{PyC}$ coating layer as represented elsewhere. ${ }^{29}$

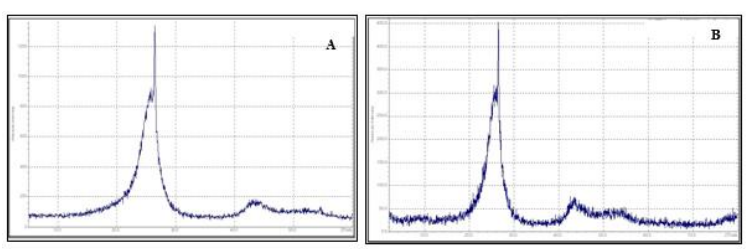

Figure 11: XRD graph A. Graphite B. PyC

Hemolytic Activity: Hemolysis means the destruction of the membranes of red blood cells (RBCs) and the release of hemoglobin in the surrounding fluid. The materials used in endoprosthesis cause inflammations, cytotoxicity, hemolysis, and other toxic effects. Therefore, before using these materials in the field of medicine, their biocompatibility and hemolytic activity must be performed. In vitro Hemolytic testing using the blood is the most common method to determine the hemocompatibility of biomaterials. The hemolytic testing of graphite and PyC was carried out according to the ASTM standard. According to ASTM Standard F756 (American Society for Testing \& Materials), if hemolytic activity of a biomaterial is $>5 \%$ then the material said to be hemolytic, hemolytic activity $>2 \%$ material fall into the category of slightly hemolytic, and the hemolytic activity $<2 \%$ material is to be considered as nonhemolytic. $^{30}$

Different levels of hemocompatibility of graphite and PyC was observed in human erythrocytes as per the ASTM F756 standard. The hemolytic activity of graphite and PyC in this paper was evaluated by the two methods, Qualitative (visual inspection method) and Quantitative analysis (through UV). 


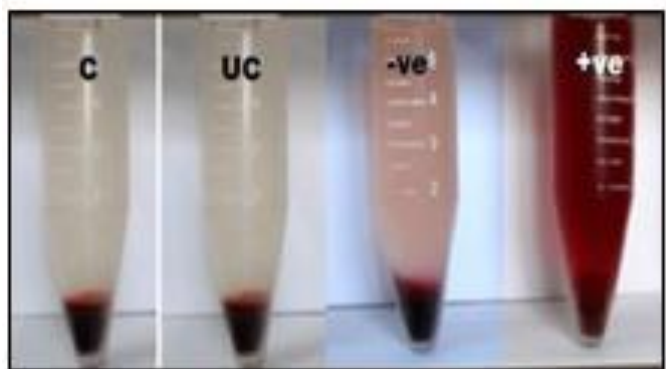

Figure 12: Qualitative analysis of materials before and after coating

The outcomes of qualitative analysis as shown in Figure 12 the positive control was seen as dark red color, which was the indication of ruptured RBCs, on the other hand in remaining tubes the supernatant was clear no RBCs destruction took place, which was confirmation of nonhemolytic properties of the coated and uncoated samples. Whereas Quantitative analysis carried out by Ultraviolet (UV) Spectrophotometry at $550 \mathrm{~nm}$ wavelength of supernatant because the absorbance range of hemoglobin molecule is $520-550 \mathrm{~nm}$. The quantitative analysis results as shown in Figure 13 revealed Graphite causes 1.4\% hemolysis and $\mathrm{PyC}$ showed $0.88 \%$ hemolysis during the hemolytic testing while negative control with $0.85 \%$ hemolysis (no reaction took place in negative control). Therefore, according to the classification of ASTM F756 standard, material causing less than $2 \%$ hemolysis is said to be non-hemolytic. The graphite and $\mathrm{PyC}$ causes less than $2 \%$ hemolysis when directly come in contact with blood as shown in Figure 13 so, they fall into the category of non-hemolytic materials according to the ASTM F756, Furthermore, PyC coating improves the hemocompatibility of base material (graphite)

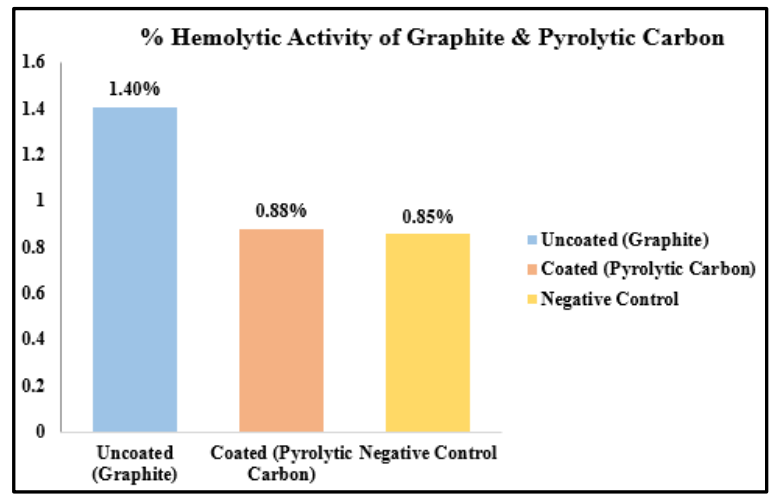

Figure 13: Hemolytic Activity of Graphite and PyC

\section{CONCLUSION}

Currently available heart valve has a short leaflet ear that provides tissue ingrowth across the orifice, which leads to restricting the leaflet movement, and few of them required long-term anticoagulation therapy. This paper focused on the design development and fabrication of bileaflet mechanical mitral heart valve for the treatment of valvular heart diseases. It was proposed that the mechanical mitral valve manufactured by the above mentioned techniques offer good hemocompatibility and less damage to blood cells. The unique features of this model are long leaflet ear, which reduces the tissue ingrowth across the orifice and provide a maximum degree of motion to the leaflets due to butterfly shape hinges and these technical and structural inspiration taken from the OnX mechanical valve model. This study also associated with the Pyrolytic Carbon (PyC) coating, and the $\mathrm{PyC}$ provides non-adhesive surfaces with good hemodynamic properties, coatings reduce the formation of blood clots by declining the pore size and the contact angel increased results low wettability. According to outcomes of the hemolytic activity carried out in this study it is verified that $\mathrm{PyC}$ and graphite are nonhemolytic they do not cause hemolysis when come in contact with blood hence these materials are suitable for cardiovascular implants. These features of the mechanical mitral heart have the advantage over commercially available heart valves.

\section{Acknowledgement}

I would like to acknowledge Dr Murtaza Najabat Ali for his immense support and guidance and Institute National University of Sciences and Technology, NUST, H-12 Islamabad for the opportunities and technologies available in the university.

\section{AUTHORS' CONTRIBUTION}

NM conducted hands-on research on heart valve design and coating under the supervision of MNA, who supervised and aligned the whole project. The design of the project, testing and analysis was conducted with the help and guidance of $\mathrm{HI}$.

Conflict of interest: Authors declared no conflict of interest.

\section{REFERENCES}

1. Puskas J, Gerdisch M, Nichols D, Quinn R, Anderson C, Rhenman $\mathrm{B}$, et al. Reduced anticoagulation after mechanical aortic valve replacement: interim results from the prospective randomized on$\mathrm{X}$ valve anticoagulation clinical trial randomized Food and Drug Administration investigational device exemption trial. Thorac Cardiovasc Surg, 2014.147(4):1202-11.

2. Cai C, Braido PN, Allan B, Ashworth PE, Kruse S, LaChance L, et al. Prosthetic heart valve including stent structure and tissue leaflets, and related methods. United States patent US 8,353,954. 2013 Jan 15.

3. Chambers, J. Prosthetic heart valves. Int $\mathrm{J}$ Clin Pract. 2014;68(10):1227-30.

4. Van de Werf F, Brueckmann M, Connolly SJ, Friedman J, Granger CB, Härtter S, et al.,A comparison of dabigatran etexilate with warfarin in patients with mechanical heart valves: THE Randomized, phase II study to evaluate the safety and pharmacokinetics of oral dabigatran etexilate in patients after heart valve replacement (RE-ALIGN). Am Heart J. 2012;163(6):931-7. 
5. Chikwe J, Chiang YP, Egorova NN, Itagaki S, Adams DH. Survival and outcomes following bioprosthetic vs mechanical mitral valve replacement in patients aged 50 to 69 years. JAMA, 2015;313(14):1435-42.

6. Dumont K, Vierendeels J, Kaminsky R, van Nooten G, Verdonck $\mathrm{P}$, Bluestein D. Comparison of the hemodynamic and thrombogenic performance of two bileaflet mechanical heart valves using a CFD/FSI model. J Biomech Eng. 2007;129(4):55865 .

7. Goldstone $\mathrm{AB}$, Chiu $\mathrm{P}$, Baiocchi M, Lingala B, Patrick WL, Fischbein MP, et al. Mechanical or biologic prostheses for aorticvalve and mitral-valve replacement. $\mathrm{N}$ Engl $\mathrm{J}$ Med. 2017;377(19):1847-57.

8. Ely JL, Emken MR, Accuntius JA, Wilde DS, Haubold AD, More $\mathrm{RB}$, et al. Pure pyrolytic carbon: preparation and properties of a new material, On-X carbon for mechanical heart valve prostheses. J Heart Valve Dis. 1998;7(6):626-32.

9. Palatianos GM, Laczkovics AM, Simon P, Pomar JL, Birnbaum DE, Greve HH, et al. Multicentered European study on safety and effectiveness of the On-X prosthetic heart valve: intermediate follow-up. Ann Thorac Sur. 2007;83(1):40-6.

10. Hauert, R. A review of modified DLC coatings for biological applications. Diam Relat Mater. 2003;12(3-7):583-9.

11. Hassler M. Other commonly used biomedical coatings: pyrolytic carbon coatings, in Coatings for biomedical applications. 2012, Elsevier. p75-105.

12. Camilleri LF, Bailly P, Legault BJ, Miguel B, D'Agrosa-Boiteux MC, de Riberolles CM. Mitral and mitro-aortic valve replacement with Sorin Bicarbon valves compared with St. Jude Medical valves. Cardiovasc Surg. 2001;9(3):272-80.

13. Baudet EM, Puel V, McBride JT, Grimaud JP, Roques F, Clerc F, et al. Long-term results of valve replacement with the St. Jude Medical prosthesis. J Thorac Cardiovasc Surg. 1995;109(5):85870.

14. Alemu Y, Girdhar G, Xenos M, Sheriff J, Jesty J, Einav S, et al. Design optimization of a mechanical heart valve for reducing valve thrombogenicity — a case study with ATS valve. ASAIO J. 2010;56(5):389-96.

15. Westaby S, Van Nooten G, Sharif H, Pillai R, Caes F. Valve replacement with the ATS open pivot bileaflet prosthesis. Eur J Cardio-thorac Surg, 1996;10:660-5.

16. Butchart EG, Li HH, Payne N, Buchan K, Grunkemeier GL. Twenty years' experience with the Medtronic Hall valve. T J Thorac Cardiovasc Surg. 2001;121(6):1090-100.
17. Nitter-Hauge S, Abdelnoor M, Svennevig JL. Fifteen-year experience with the medtronic-hall valve prosthesis. A follow-up study of 1104 consecutive patients. Circulation. 1996;94(9 Suppl):II105-8.

18. Mirkhani N, Davoudi MR, Hanafizadeh P, Javidi D, Saffarian N. On-X heart valve prosthesis: numerical simulation of hemodynamic performance in accelerating systole. Cardiovasc Eng Technol. 2016.7(3):223-37.

19. Bajpai V, Salhotra G, Singh RK, Orthogonal micro-grooving of anisotropic pyrolytic carbon. Mater Manuf Process. 2011;26(12):1481-93.

20. Lund O, Bland M. Risk-corrected impact of mechanical versus bioprosthetic valves on long-term mortality after aortic valve replacement. J Thorac Cardiovasc Surg. 2006;132(1):20-6.

21. Schroeter RB, Kratochvil R, Gomes J de O. High-speed finishing milling of industrial graphite electrodes. J Mater Process Technol. 2006;179(1-3):128-32.

22. Feng Z, Nakamura T, Fujimoto T, Umezu M. In vitro investigation of opening behavior and hydrodynamics of bileaflet valves in the mitral position. Artif Organs, 2002;26(1):32-9.

23. Wu C, Hwang NHC, Lin YK. A parametric study of hertzian contact stresses in pyrolytic carbon/graphite composite. Cardiovasc Eng: 2002;2(2):49-56.

24. Henkelman S, Rakhorst G, Blanton J, van Oeveren W. Standardization of incubation conditions for hemolysis testing of biomaterials. Mater Sci Eng. 2009;29(5):1650-4.

25. Gould LA, Lansley AB, Brown MB, Forbes B, Martin GP. Mitigation of surfactant erythrocyte toxicity by egg phosphatidylcholine. J Pharm Pharmacol. 2000;52(10):1203-9.

26. Arabi H, Mirzadeh H, Ahmadi SH, Amanpour S, Rabbani S, Abdi A. In vitro and in vivo hemocompatibility evaluation of graphite coated polyester vascular grafts. Int $\mathrm{J}$ Artif Organs. 2004;27(8):691-8.

27. Forti S, Lunelli L, Volpe CD, Siboni S, Pasquardini L, lui A, et al. Hemocompatibility of pyrolytic carbon in comparison with other biomaterials. Diam Relat Mater. 2011;20(5-6):762-9.

28. Kartick B, Srivastava SK, Srivastava I. Green synthesis of graphene. J Nanosci Nanotechnol. 2013;13(6):4320-4.

29. He X, Song J, Xu L, Tan J, Xia H, Zhang B, et al. Protection of nuclear graphite toward liquid fluoride salt by isotropic pyrolytic carbon coating. J Nucl Mater. 2013;442(1-3):306-8.

30. Elahi MF, Guan GP, Wang L. Hemocompatibility of surface modified silk fibroin materials: A review. Rev Adv Mater Sci. 2014:38(2):148-59.

\section{Address for Correspondence:}

Dr. Murtaza Najabat Ali, Biomedical Engineering and Sciences Department (BMES), School of Mechanical and Manufacturing Engineering (SMME), National University of Sciences \& Technology (NUST), Islamabad, Pakistan.

Email: murtaza.bme@ hotmail.com 